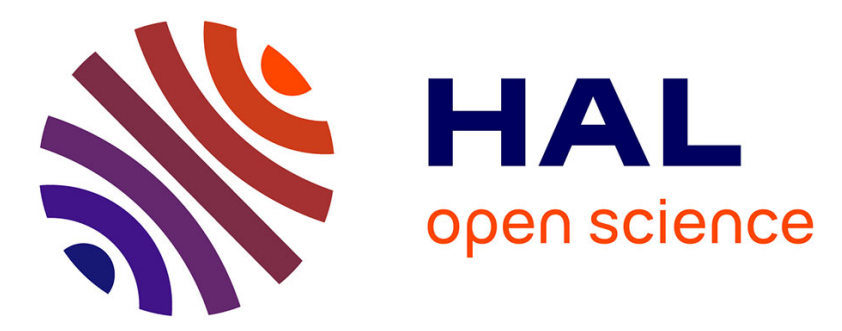

\title{
Gate and drain low frequency noise of ALGaN/GaN HEMTs featuring high and low gate leakage currents
}

\author{
Serge Karboyan, Jean-Guy Tartarin, N Labat, B. Lambert
}

\section{To cite this version:}

Serge Karboyan, Jean-Guy Tartarin, N Labat, B. Lambert. Gate and drain low frequency noise of ALGaN/GaN HEMTs featuring high and low gate leakage currents. 22nd International Conference on Noise and Fluctuations (ICNF 2013), Jun 2013, Montpellier, France. 10.1109/ICNF.2013.6578954 . hal-01343429

\section{HAL Id: hal-01343429 \\ https://hal.science/hal-01343429}

Submitted on 8 Jul 2016

HAL is a multi-disciplinary open access archive for the deposit and dissemination of scientific research documents, whether they are published or not. The documents may come from teaching and research institutions in France or abroad, or from public or private research centers.
L'archive ouverte pluridisciplinaire HAL, est destinée au dépôt et à la diffusion de documents scientifiques de niveau recherche, publiés ou non, émanant des établissements d'enseignement et de recherche français ou étrangers, des laboratoires publics ou privés. 


\section{Gate and Drain Low Frequency Noise of AlGaN/GaN HEMTs Featuring High and Low Gate Leakage Currents}

\author{
S. Karboyan, J.G. Tartarin \\ LAAS - CNRS and University of \\ Toulouse \\ Toulouse, France
}

\author{
N. Labat \\ IMS and University of Bordeaux \\ Bordeaux, France
}

\author{
B. Lambert \\ United Monolithic Semiconductor \\ Villebon sur Yvette, France
}

\begin{abstract}
The qualification of a technology needs rigorous and numerous stress experiments to attest of a high level of reliability. Low frequency noise measurements are known as an effective characterization method for the evaluation of device reliability. This technique is usually applied on the drain current spectral density, but it is now largely accepted that the gate access is a major reliability indicator. Moreover, devices featuring slight differences in their drain current noise can be subjected to strong differences on their gate leakage currents, and as a consequence on the current low frequency noise (LFN). In the present work, LFN measurements are investigated on the gate and drain currents of two sets of $\mathrm{AlGaN} / \mathrm{GaN}$ high electron mobility transistors (HEMTs) with high and low gate leakage currents. It is demonstrated that devices featuring weak differences on their drain current can be subjected to strong differences on their gate leakage signatures: moreover, it is found that the high leakage current can generate numerous traps under the gated zone of the transistor, leading to a change of the intrinsic tuning voltage and by consequence of the number of carriers, thus explaining the reduction on the drain current. The transistors show a difference of 3 to 4 decades on their gate current noise and a negligible shift of $20 \%$ on their drain current noise. The large variations on the gate LFN signatures between the two sets of devices, and the induced charges for the leaky devices can probably be related with large differences on the expected lifetimes for the devices under test.
\end{abstract}

Keywords-AlGaN/GaN HEMT; Low frequency noise; gate leakage current; gate current noise spectral density; drain current noise spectral density.

\section{INTRODUCTION}

$\mathrm{GaN}$ technologies are pointed out as promising candidates for high power $[1,2]$, high frequency, high breakdown voltages $[3,4]$ and low noise circuits and systems. At this day, $\mathrm{AlGaN} / \mathrm{GaN}$ high electron mobility transistors (HEMTs) still suffer of weak robustness against stresses if used at their DCRF electrical limits [5-8]. The limiting mechanisms must thus be studied to propose stronger reliable technologies and to push the limits for longer operating times. If electrical characterizations represent a first order parameter to consider for qualifying a process, low frequency noise (LFN) measurements are helpful for getting deeper information about the nature of the defects and their evolution before and after application of the stress $[9,10]$, as far as it is a non destructive technique. In this paper, gate and drain noise current spectral densities (respectively $\mathrm{S}_{\mathrm{IG}}$ and $\mathrm{S}_{\mathrm{ID}}$ ) are investigated on AlGaN/GaN HEMTs featuring high (T1) and low (T2) gate leakage currents. As the gate access is recognized to be the place around which many defects appear during the application of different stresses, therefore the next study is essentially focused on the gate leakage current $\mathrm{I}_{\mathrm{G}}$ and to its noise spectral densities $\mathrm{S}_{\mathrm{IG}}$. On the other hand, as $\mathrm{S}_{\mathrm{ID}}$ is associated to the noise between drain and source, it can be investigated to design low noise non-linear devices for applications such as mixers or low noise oscillators $[11,12]$. The spectra will be presented to demonstrate the absence of correlation between the two LFN measurements related to the gate current and to the channel current.

The paper is organized as follows. In section II, we describe the technological parameters of the devices structures. In the same section, the experimental conditions are also mentioned followed by the electrical characterizations. Sections III and IV report on the gate and drain LFN measurements respectively for leaky and non-leaky devices. Section V sets the conclusions drawn from the study.

\section{DEVICES UNDER TEST AND EXPERIMENTAL CONDITIONS}

\section{A. Devices under test}

The AlGaN/GaN HEMTs under test are fabricated at United Monolithic Semiconductors (UMS) [13]. They are grown on $\mathrm{SiC}$ substrate and feature $18 \%$ of $\mathrm{Al}$ content. The surface is SiN passivated and the Schottky contact is formed by deposition of $\mathrm{Ni} / \mathrm{Pt} / \mathrm{Au}$ transition metals. The devices feature four gate fingers $(4 \times 400 \mu \mathrm{m} \times 0.5 \mu \mathrm{m})$ as shown in Fig. 1 . The set selected from the same wafer is composed of devices presenting high gate leakage currents ( $\mathrm{T} 1$ with an $\mathrm{I}_{\mathrm{G}}$ of $855 \mu \mathrm{A} / \mathrm{mm}$ at $\mathrm{V}_{\mathrm{DS}}=50 \mathrm{~V}$ and $\left.\mathrm{V}_{\mathrm{GS}}=-7 \mathrm{~V}\right)$ and low gate leakage currents (T2 with an $\mathrm{I}_{\mathrm{G}}$ of $265 \mu \mathrm{A} / \mathrm{mm}$ under same biasing conditions). 


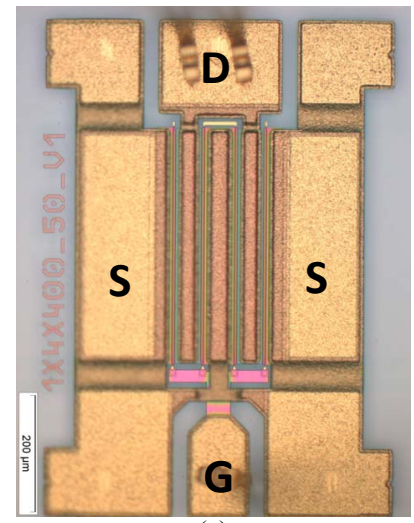

(a)

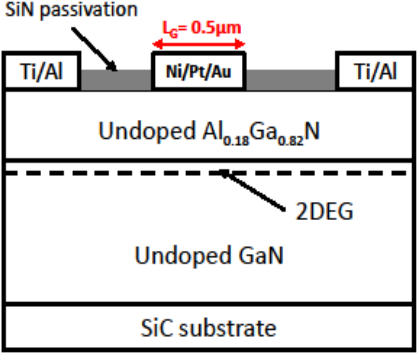

(b)
Fig. 1. AlGaN/GaN HEMTs under test.

(a) Top view of the devices under test (4 gate fingers).

(b) Transversal schematic illustration of the mono-finger device.

\section{B. Experimental conditions and electrical characterization}

DC current voltage measurements are performed using an Agilent $4156 \mathrm{C}$ at room temperature. Fig. 2 shows $\mathrm{IG}_{\mathrm{G}}\left(\mathrm{V}_{\mathrm{GS}}\right)$ characteristics of the Schottky diode (open drain) and of the transistor when $\mathrm{V}_{\mathrm{DS}}$ is biased from 0 to $8 \mathrm{~V}$. A similar trend to that of the Schottky diode is obtained when the device is shorted at the drain access (with a slight increase on $\mathrm{I}_{\mathrm{G}}$ ). This study focuses on the two extreme $\mathrm{I}_{\mathrm{G}}$ plots extracted from our measurements (the diode alone and the transistor mode at $\left.\mathrm{V}_{\mathrm{DS}}=8 \mathrm{~V}\right)$. A difference in the gate leakage current is observed between $\mathrm{T} 1$ and $\mathrm{T} 2$.

Fig. 3 illustrates the $\mathrm{I}_{\mathrm{D}}\left(\mathrm{V}_{\mathrm{DS}}\right)$ DC measurements. The difference noticed on the drain currents of $\mathrm{T} 1$ and $\mathrm{T} 2$ remains weak in comparison with their gate currents, but it is important to take it into account. Thus, no significant difference is noticed between $\mathrm{T} 1$ and $\mathrm{T} 2$ on their drain current (DC and pulsed measurements), and it could be easily assumed that T1 and T2 could be independently used for a given application (see also $\mathrm{S}_{\mathrm{ID}}$ in section IV) if only the drain current is considered.

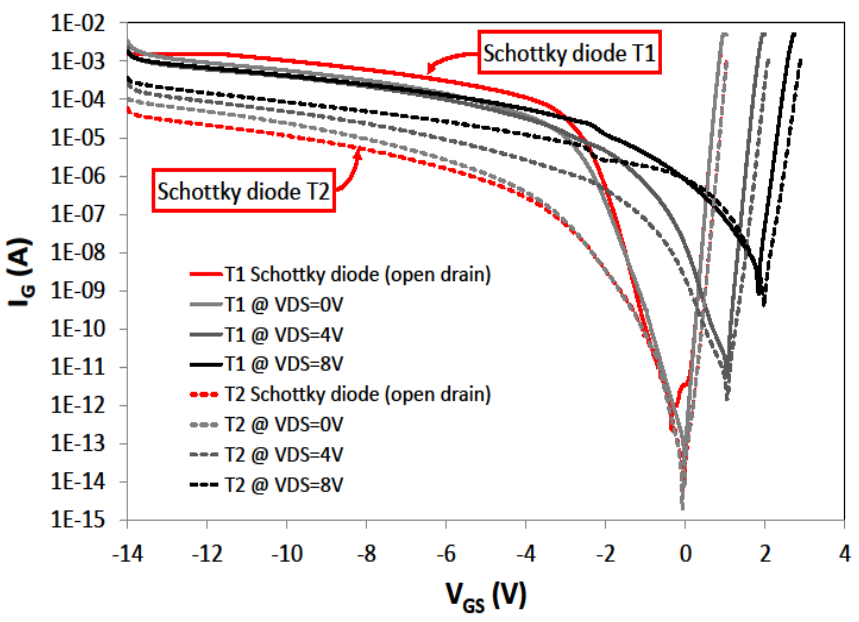

Fig. 2. $\mathrm{DC} \mathrm{I}_{\mathrm{G}}-\mathrm{V}_{\mathrm{GS}}$ gate characteristics of $\mathrm{T} 1$ and $\mathrm{T} 2$ devices. red curves (dashed and solid lines): the Schottky diode grey to black: The transistor biased from $\mathrm{V}_{\mathrm{DS}}=0 \mathrm{~V}, 4 \mathrm{~V}, 8 \mathrm{~V}$.

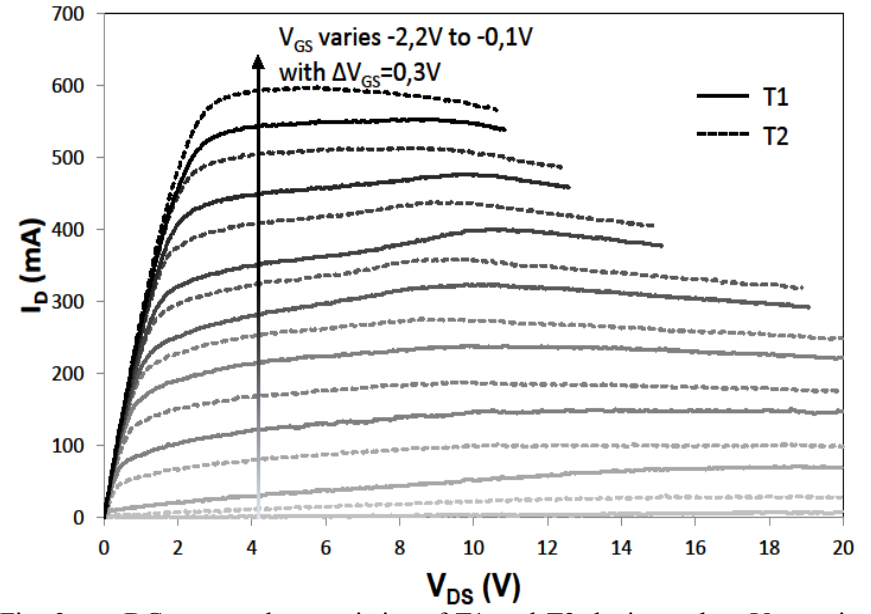

Fig. 3. DC output characteristics of $\mathrm{T} 1$ and $\mathrm{T} 2$ devices when $\mathrm{V}_{\mathrm{GS}}$ varies from $-2.2 \mathrm{~V}$ to $-0.1 \mathrm{~V}$ with a step of $0.3 \mathrm{~V}$.

The solid and dashed lines correspond to $\mathrm{T} 1$ and $\mathrm{T} 2$ respectively.

The LFN measurements are performed at room temperature in the frequency range of $1 \mathrm{~Hz}$ to $100 \mathrm{kHz}$ using Model 5182 transimpedance amplifier for the gate current noise measurements (the conversion gain is set to $10^{6} \mathrm{~V} / \mathrm{A}$ ). A Model 5184 voltage amplifier is also used for the drain current noise measurements. To reduce interferences with the external environment, the measurements are carried out in a shielded room. The amplifiers are connected to HP89410A vector signal analyzer and to a computer program to monitor and collect the results.

The gate current noise measurements are carried out under reverse biases on the Schottky diode (open drain configuration) and when the transistor is biased at $\mathrm{V}_{\mathrm{DS}}=8 \mathrm{~V}$. On the other hand, drain current noise measurements are also performed under constant $\mathrm{V}_{\mathrm{GS}}$ and when $\mathrm{V}_{\mathrm{DS}}$ varies in saturated region $\left(5 \mathrm{~V} \leq \mathrm{V}_{\mathrm{DS}} \leq 8 \mathrm{~V}\right)$.

\section{GATE CURRENT LFN CHARACTERIZATION}

The gate noise current measurements performed on $\mathrm{T} 1$ and T2 are presented in Fig. 4 as follows: Fig. $4 \mathrm{a}$ and $4 \mathrm{~b}$ show the measurements carried out on the Schottky diodes and on the transistor at $\mathrm{V}_{\mathrm{DS}}=8 \mathrm{~V}$ respectively for $\mathrm{T} 1$ and $\mathrm{T} 2$.

The non-leaky device T2 features almost the same scattering of the spectra than for $\mathrm{T} 1$ when considering the common biasing range (approximately 2 decades). However, it is found that a difference of more than four decades is noticeable between the gate noise current densities of $\mathrm{T} 1$ and T2: this is relevant with the difference found on DC leakage currents from Fig. 2 (more than 2 decades at $\mathrm{V}_{\mathrm{GS}}=-2 \mathrm{~V},-3 \mathrm{~V}$, $5 \mathrm{~V})$. Moreover, the noise evolution of T2 non-leaky device follows a $1 / \mathrm{f}$ behavior while $\mathrm{T} 1$ spectra are mainly composed by numerous generation-recombination (GR) centers (mainly in the lower frequency band), that mask the $1 /$ f noise source. At first, this reveals a large number of traps and defects directly related to the degradation of the leakage current for T1 device. 
TABLE I. GATE CURRENT VALUES

\begin{tabular}{|c|c|c|c|c|c|c|}
\hline & $V_{G S}(V)$ & -2 & -3 & -5 & -7 & -9 \\
\hline \multirow{2}{*}{$\begin{array}{c}\text { T1 } \\
\text { (Leaky } \\
\text { device) }\end{array}$} & $\begin{array}{l}I_{G}(\text { Schottky } \\
\text { diode })(\mu \mathrm{A})\end{array}$ & 0.25 & 7.1 & 37 & 97 & 210 \\
\hline & $\begin{array}{c}\mathbf{I}_{\mathrm{G}} \text { (Transistor at } \\
\left.\mathbf{V}_{\mathrm{DS}}=\mathbf{8 V}\right)(\boldsymbol{\mu} \mathrm{A})\end{array}$ & - & 36.5 & 80 & 160 & 300 \\
\hline \multirow{2}{*}{$\begin{array}{c}\text { T2 } \\
\text { (Non-leaky } \\
\text { device) }\end{array}$} & $\begin{array}{l}I_{G}(\text { Schottky } \\
\text { diode }(\mu \mathrm{A})\end{array}$ & - & - & 0.64 & 2.8 & 7.4 \\
\hline & $\begin{array}{c}\mathrm{I}_{\mathrm{G}} \text { (Transistor at } \\
\left.\mathrm{V}_{\mathrm{DS}}=8 \mathrm{~V}\right)(\mu \mathrm{A})\end{array}$ & 1.12 & 4 & 8 & 14 & 23.5 \\
\hline
\end{tabular}

These traps can be the precursors of failure degradation modes when the devices are stressed. Table 1 synthesizes the gate current values from the LFN measurements extracted at different biases under each configuration for $\mathrm{T} 1$ and $\mathrm{T} 2$.

The results reveal the strong difference on the gate access between the two devices: the current leakage kinetic is also of different nature between $\mathrm{T} 1$ and $\mathrm{T} 2$ as the electrons are neither subjected to the same mechanism nor following the same conduction path (leakage current between gate and source). As the gate Schottky pad controls the carriers flowing in the channel between source and drain, the gate stability and conduction mechanisms are of prime importance to assess the reliability of a technology. The drain noise current spectral densities are presented in the next section.

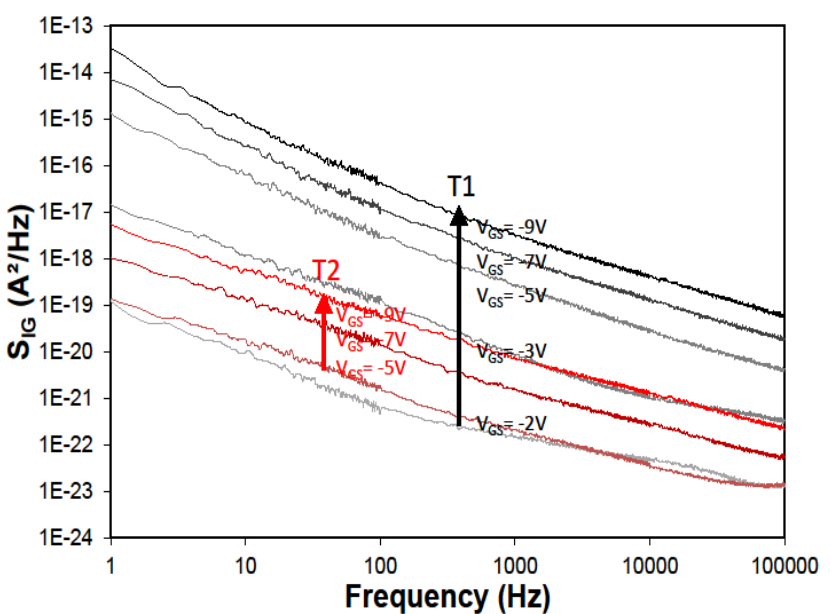

(a)

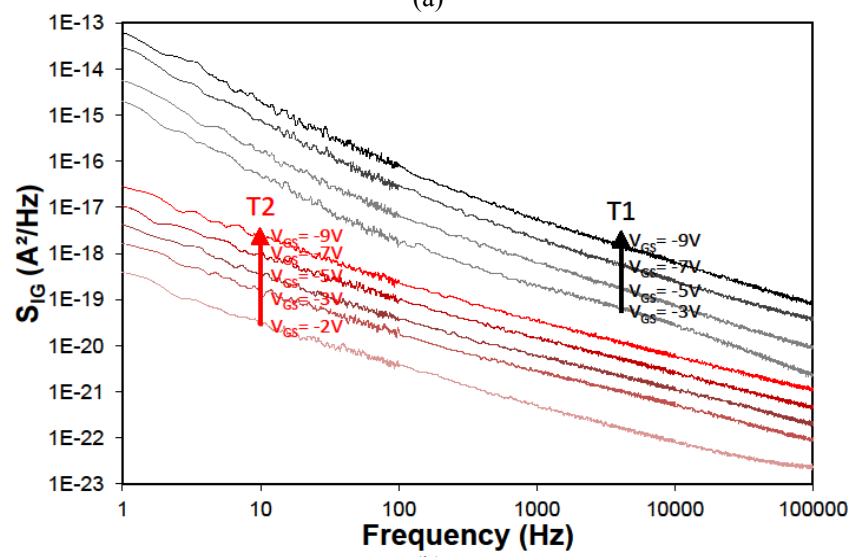

(b)

Fig. 4. Gate noise current spectral density of the AlGaN/GaN HEMTs. (a) of the Schottky diodes (open drain).

(b) of the transistors biased in the saturation region at $\mathrm{V}_{\mathrm{DS}}=8 \mathrm{~V}$.

\section{DRAIN CURRENT LFN CHARACTERIZATION}

As the drain current and drain LFN spectra are the first parameters to consider for non linear applications such as $\mathrm{VCO}$, mixer, etc., the study of $\mathrm{S}_{\mathrm{ID}}$ can be used to design low noise non-linear circuits. Fig. 5 shows the drain current noise measurements normalized versus the drain current $\left(\mathrm{S}_{\mathrm{ID}} / \mathrm{I}_{\mathrm{D}}\right)$ for $\mathrm{T} 1$ and $\mathrm{T} 2$ at $\left(\mathrm{V}_{\mathrm{GS}}=-1.3 \mathrm{~V}, \mathrm{~V}_{\mathrm{DS}}=5 \mathrm{~V}\right)$ and $\left(\mathrm{V}_{\mathrm{GS}}=-1.3 \mathrm{~V}, \mathrm{~V}_{\mathrm{DS}}=8 \mathrm{~V}\right)$. From the gate current noise measurements, it is noticeable that more GR centers are masking the $1 / \mathrm{f}$ behavior of $\mathrm{T} 1$ in comparison with T2 spectra. These GR centers have a strong impact on the trapping mechanisms of the carriers: the presence of these traps are clearly evidenced by the presence of GR centers in the lower frequency band (below 100Hz) more pronounced for the leaky device than for the non leaky devices. Even if no correlation has been found between $\mathrm{S}_{\mathrm{IG}}$ and $\mathrm{S}_{\mathrm{ID}}$ spectra, it is noticeable that leaky devices present higher number of charges (as shown in Fig. 4) in the vicinity of the gate (surface and volume charges). . Moreover, when the biasing changes from $\mathrm{V}_{\mathrm{DS}}=5 \mathrm{~V}$ to $\mathrm{V}_{\mathrm{DS}}=8 \mathrm{~V}$ (constant $\mathrm{I}_{\mathrm{DS}}$, devices are quasi thermally stable), the space charge region evolves for both $\mathrm{T} 1$ and $\mathrm{T} 2$, and charges can be created between gate and drain terminals. The bias dependant charge variation under the gated zone and between gate and drain of the two types of devices can be the cause of an intrinsic modification of the gate control of the carriers (Schottky diode) $[14,15]$. As a consequence of a higher number of charges close to the gate controlled-zone, the drain current $I_{D S}$ is reduced by $13 \%$ for the leaky devices (positive charges are located beneath the gate metallization whereas negative charges are positioned on the opposite side at the $\mathrm{AlGaN} / \mathrm{GaN}$ interface). This phenomenon is observed on the DC and pulsed $\mathrm{I}_{\mathrm{DS}}-\mathrm{V}_{\mathrm{DS}}$ characteristics as well as on $\mathrm{S}_{\mathrm{ID}} / \mathrm{I}_{\mathrm{D}}$ LFN measurements for $\mathrm{T} 1$ and $\mathrm{T} 2$. When considering the normalized drain current noise spectral density in Fig. 5, leaky and non-leaky devices feature almost the same normalized noise level for frequencies above $100 \mathrm{~Hz}$, whereas the noise behavior in the lower frequency band largely differs between these two sets of devices. Once again, the traps involved between $1 \mathrm{~Hz}-100 \mathrm{~Hz}$ can be associated with a higher density of charges for the leaky device under the gated zone (with time constants ranging from $5 \mathrm{~ms}$ to few seconds, also revealed by transient measurements).

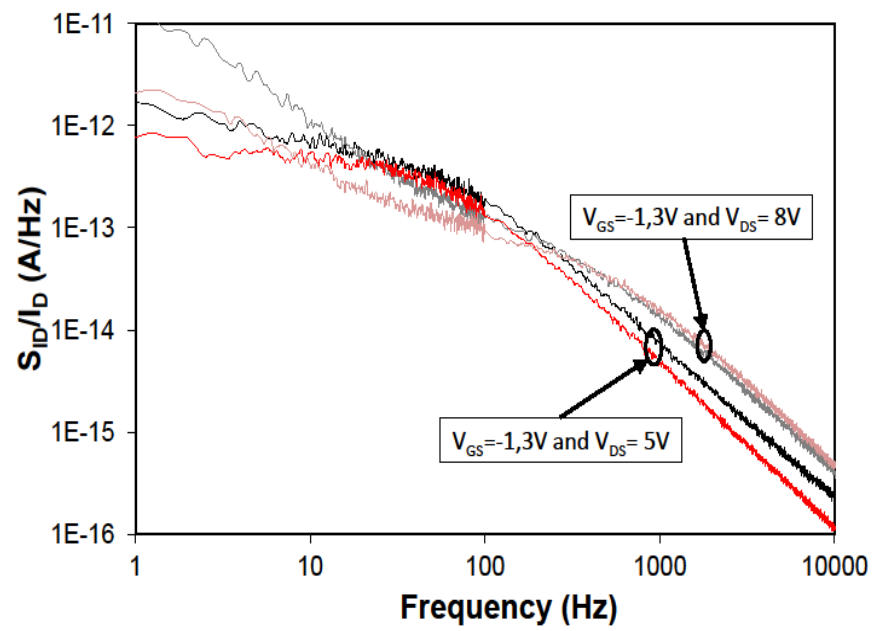

Fig. 5. Drain noise current spectral densities of $\mathrm{T} 1$ and $\mathrm{T} 2$ at $\mathrm{V}_{\mathrm{GS}}=-1.3 \mathrm{~V}$ and $\mathrm{V}_{\mathrm{DS}}=5 \mathrm{~V}$ and $8 \mathrm{~V}$. The grey and red plots correspond to $\mathrm{T} 1$ and $\mathrm{T} 2$ respectively. 
TABLE II. DRAIN CURRENT VALUES

\begin{tabular}{|c|c|c|c|c|}
\cline { 2 - 5 } \multicolumn{1}{c|}{} & $\mathbf{V}_{\mathbf{G S}}(\mathbf{V})$ & -1.9 & -1.6 & -1.3 \\
\hline $\begin{array}{c}\text { T1 } \\
\text { (Leaky device) }\end{array}$ & $\begin{array}{c}\mathbf{I}_{\mathbf{D}} \text { (Transistor at } \\
\left.\mathbf{V}_{\mathbf{D S}}=7 \mathbf{V}\right)(\mathbf{m A})\end{array}$ & 85 & 170 & 250 \\
\hline $\begin{array}{c}\mathbf{T} 2 \\
\text { (Non-leaky device) }\end{array}$ & $\begin{array}{c}\mathbf{I}_{\mathbf{D}}(\mathbf{T r a n s i s t o r} \text { at } \\
\left.\mathbf{V}_{\mathbf{D S}}=\mathbf{7 V}\right)(\mathbf{m A})\end{array}$ & 55 & 130 & 218 \\
\hline
\end{tabular}

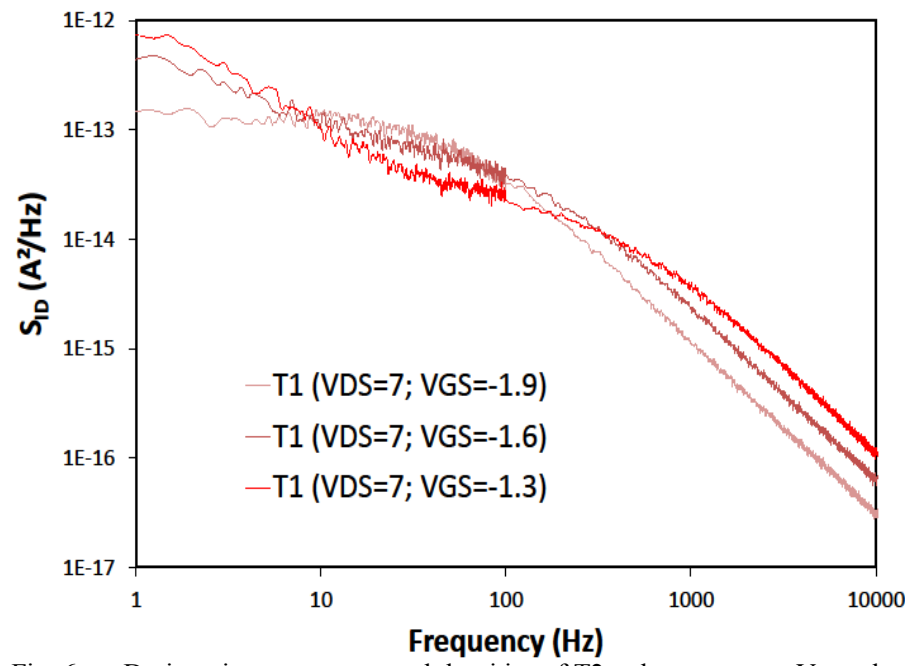

Fig. 6. Drain noise current spectral densities of $\mathrm{T} 2$ only at constant $\mathrm{V}_{\mathrm{DS}}$ value of $7 \mathrm{~V}$ and at $\mathrm{V}_{\mathrm{GS}}=-1.9$ to $-1.3 \mathrm{~V}$ with $\Delta \mathrm{V}_{\mathrm{GS}}=0.3 \mathrm{~V}$.

Fig. 6 presents the drain noise current measurements carried out on and $\mathrm{T} 2$ at constant $\mathrm{V}_{\mathrm{DS}}$ of $7 \mathrm{~V}$ when $\mathrm{V}_{\mathrm{GS}}$ varies from 1.9 to $-1.3 \mathrm{~V}$ by step of $0.3 \mathrm{~V}$; It can be assumed that the device is sensitive to the thermal steady state of the channel as first order considerations $\left(\mathrm{P}_{\mathrm{DC}}=\mathrm{V}_{\mathrm{DS}} \cdot \mathrm{I}_{\mathrm{DS}}\right)$. Similar trends and noise levels are found for $\mathrm{T} 1$ and $\mathrm{T} 2$ devices. The GR centers extracted between $10 \mathrm{~Hz}$ and $1 \mathrm{kHz}$ are thermally activated (as shown in Fig. 6); the time constant of the involved traps decrease when the temperature increases (using a first order assumption considering the temperature to be proportional to $\left.\mathrm{P}_{\mathrm{DC}}=\mathrm{I}_{\mathrm{D}} \cdot \mathrm{V}_{\mathrm{DS}}\right)$.

Table 2 synthesizes the drain current values from the LFN measurements extracted at constant $\mathrm{V}_{\mathrm{DS}}$ of $7 \mathrm{~V}$ and when $\mathrm{V}_{\mathrm{GS}}$ varies from $-1.9 \mathrm{~V}$ to $-1.3 \mathrm{~V}$ for $\mathrm{T} 1$ and $\mathrm{T} 2$. Lastly, the only drain current analysis (DC, pulsed or LFN) is not convenient to evidence a possible evolution of the gate controlled charges in the 2DEG (as a consequence of the gate access evolution versus stress).

\section{CONCLUSION}

The paper presents a synthesis of gate and drain LFN measurements on two devices from two sets of samples featuring high and low gate leakage currents. A strong difference is revealed on the gate and drain current values between the leaky and non-leaky devices, hence on their LFN signatures, butno correlation is measured between $\mathrm{S}_{\mathrm{IG}}$ and $\mathrm{S}_{\mathrm{ID}}$ even for leaky devices. The device featuring high leakage current (T2) shows a decrease on its drain current, as a consequence of a more pronounced change in the effective barrier height for the leaky device due to the presence of a larger quantity of charges under the gated zone (revealed by $\mathrm{S}_{\mathrm{IG}}$ spectra). The drain current reduction is thus attributed to gate related charges that tune the number of carriers in the channel.

The results highlight on the impact of the gate leakage current on the drain current: the mastering of the gate in order to reduce the leakage current is a key point both for getting high drain current levels and for limiting some stress induced mechanisms leading to a reduction of the lifetime of the devices.

\section{ACKNOWLEDGMENT}

The authors would like to thank ANR for the funding of $\mathrm{ReAGaN}$ research program and all the partners of this project for fruitful discussions.

\section{REFERENCES}

[1] R. S. Pengelly, S. M. Wood, J. W. Milligan, S. T. Sheppard and W. L. Pribble, "A review of $\mathrm{GaN}$ on $\mathrm{SiC}$ high electron mobility transistors and MMICs," IEEE Transaction on Microwave Theory anf Techniques, Vol. 60, No. 6, June 2012.

[2] J.Y. Kwack, K. W. Kim and S. Cho, "1kW S-band Solid State Radar Amplifier," $12^{\text {th }}$ Wireless and Microwave Technology Conference, 2011 .

[3] N. Tipirneni, A. Koudymov, V. Adivarahan, J. Yang, G. Simin and M. Asif Khan, "The 1.6-kV AlGaN/GaN HFETs," IEEE Electron Device Letters, Vol. 27, No. 9, pp. 716-719, September 2006.

[4] B. Lu and T. Palacios, "High breakdown AlGaN/GaN HEMTs by substrate transfer technology," IEEE Electron Device Letters, Vol. 31, No. 9, pp. 951-953, September 2010.

[5] J. A. del Alamo and J. Joh, "GaN HEMT reliability," Microelectronics reliability 49 (2009), pp. 1200-1206, 2009.

[6] G. Meneghesso, G. Verzellesi, F. Danesin, F. Rempazo, F. Zanon, A. Tazzoli, M. Meneghini and E. Zanoni, "Reliability of GaN HEMTs: state od the art and perspectives," IEEE Transaction on Device and Materials Relaibility, Vol. 8, No. 2, pp. 332-343, June 2008.

[7] U. Mishra, P. Parikh and Y.F. Wu, "AlGaN/GaN HEMTs - an overview of device operation and applications," Proceedings of the IEEE, Vol. 90, Issue 6, pp. 1022-1031, June 2002.

[8] D. Marcon, T. Kauerauf and al., "A comprehnesive reliability investigation of the voltages, temperature and device geometry dependence of the gate degradation on the state-of-the-art GaN on $\mathrm{Si}$ HEMTs," IEEE International Electron Devices Meeting, 2010.

[9] L. K. J. Vandamme, "Noise as a diagnostic tool for quality and reliability of electronic devcies," IEEE Transactions on Electon Devices, 41, No. 11, 1994, pp. 2176-2187.

[10] J. Graffeuil and R. Plana, "Low frequency noise properties of microwave transistors and their applications to circuit design," $24^{\text {th }}$ European Microwave Conference, 1994.

[11] L.K.J. Vandamme, D. Rigaud, J.M. Peransin, R. Alabedra and J.M. Dumas, "Gate current $1 / \mathrm{f}$ noise in GaAs MESFET's," IEEE Transactions on Electon Devices, 35, No. 7, 1998, pp. 1071-1075.

[12] J. Lee and I. K. Han, "Low frequency noise in gate current of HEMT structures," Noise in physical systems and 1/f fluctuations, ICNF 2001.

[13] www.ums-gaas.com

[14] J. G. Tartarin, "Diagnostic tools for accurate reliability investigations of GaN devices," $21^{\text {st }}$ International Conference on Noise and Fluctuations, pp. 452-457, June 2011.

[15] S. Karboyan, J.G. Tartarin, D. Carisetti and B. Lambert, “Analysis and path localization of gate current in AlGaN/GaN HEMTs using low frequency noise measurements and optical beam induced resistance change technique," Interation Microwave Symposium (IMS), June 2013. 